\title{
Respostas na germinação e no crescimento inicial de rabanete sob ação de extrato aquoso de Piper mikanianum (Kunth) Steudel
}

\author{
Junior Borella ${ }^{1,4}$, Emanuela Garbin Martinazzo ${ }^{1}$, Tiago Zanatta Aumonde², Luciano do Amarante ${ }^{3}$,
} Dario Munt de Moraes ${ }^{1}$ e Francisco Amaral Villela ${ }^{2}$

Recebido em 22/11/2011. Aceito em 2/03/2012

\begin{abstract}
RESUMO
(Respostas na germinação e no crescimento inicial do rabanete sob ação de extrato aquoso de Piper mikanianum (Kunth) Steudel). Este trabalho objetivou avaliar os efeitos alelopáticos de folhas de pariparoba sobre a germinação e o crescimento inicial do rabanete (Raphanus sativus L.). Foram utilizados extratos de folhas maduras frescas nas concentrações 2 , 4 e $8 \%(\mathrm{p} / \mathrm{v})$, cujo $\mathrm{pH}$ e potencial osmótico foram aferidos. No bioensaio de germinação foram empregadas cinco repetições de 25 sementes distribuídas em placas de petri forradas com papel Germitest, umedecido com $7 \mathrm{~mL}$ de extrato ou água e mantidos a $25^{\circ} \mathrm{C}$ em B.O.D. por cinco dias. A porcentagem de germinação (PG), velocidade de germinação (VG), índice de velocidade de germinação (IVG) e índice de efeito alelopático (RI) foram determinados. No bioensaio de crescimento inicial, sementes germinadas até atingirem $2 \mathrm{~mm}$ de protusão radicular foram transferidas para caixas Gerbox contendo papel Germitest e $15 \mathrm{~mL}$ de extrato ou água, permanecendo sete dias a $25^{\circ} \mathrm{C}$ em B.O.D. para a avaliação do comprimento da radícula e do hipocótilo, da massa fresca e seca, do conteúdo de água e do teor de clorofila ( $a, b$ e total). Todos os parâmetros de germinação (PG, VG, IVG e RI) foram afetados negativamente pelos extratos de P. mikanianum. O crescimento inicial foi influenciado pelos extratos, resultando em redução do comprimento da radícula e aumento do hipocótilo. Além disso, os extratos causaram redução da biomassa fresca e do conteúdo de água a $8 \%$ e incrementos dos teores de clorofila $b$ e total a 2 e $4 \%$. Assim, a espécie Piper mikanianum exerce efeito alelopático sobre o rabanete.
\end{abstract}

Palavras-chave: alelopatia, qualidade fisiológica, pariparoba, Raphanus sativus

\begin{abstract}
(Responses in germination and early growth of radish under the influence of an aqueous extract of Piper mikanianum (Kunth) Steudel). This study evaluated the allelopathic effects of an extract from P. mikanianum leaves on the germination and early growth of radish (Raphanus sativus L.). Leaf extracts were prepared at concentrations of 2, 4 and $8 \%$. The $\mathrm{pH}$ and osmotic potential of the extracts were determined. Germination bioassay consisted of five replicates of 25 radish seeds distributed in Petri dishes with germitest paper and $7 \mathrm{~mL}$ of extract or water, and were kept at $25^{\circ} \mathrm{C}$ in B.O.D. for five days. Germination percentage (PG), germination speed (VG), germination speed index (IVG) and index of allelopathic effect (RI) were determined. For bioassay initial growth, seeds were germinated until the protrusion of the radicle was $2 \mathrm{~mm}$ and transferred to Gerbox boxes containing germitest paper and $15 \mathrm{~mL}$ of extract or water, which were kept for seven days at $25^{\circ} \mathrm{C}$ in B.O.D. to evaluate the length of the radicle and hypocotyl, fresh and dry mass, water content and chlorophyll content ( $a, b$ and total). Leaf extracts from $P$. mikanianum negatively affected all parameters examined for germination (PG, VG, IVG and RI). The extracts affected the initial growth, causing reduction of the radicle length and stimulating the growth of the hypocotyl. In addition, the extracts at $8 \%$ concentration reduced fresh weight and water content. Extracts at concentrations of 2 and $4 \%$ increased the content of chlorophyll $b$ and total chlorophyll. Thus, Piper mikanianum exerted an allelopathic effect on radish.
\end{abstract}

Key words: allelopathy, physiological quality, Piper mikanianum, Raphanus sativus

\footnotetext{
1 Universidade Federal de Pelotas, Departamento de Botânica, Pelotas, RS, Brasil

2 Universidade Federal de Pelotas, Departamento de Fitotecnia, Pelotas, RS, Brasil

3 Universidade Federal de Pelotas, Centro de Ciências Químicas, Farmacêuticas e de Alimentos, Pelotas, RS, Brasil

4 Autor para correspondência: borellaj@gmail.com
} 


\section{Introdução}

As plantas produzem metabólitos determinados como aleloquímicos e, por meio de interações bioquímicas, esses compostos afetam a germinação e o crescimento de outras plantas, mecanismo definido como alelopatia (Inderjit \& Duke 2003), conforme nomeado por Molisch em 1937 (Rice 1984). Diversos são os compostos atualmente conhecidos e dotados de efeito alelopático (Rizvi et al. 1992; Pedrol et al. 2006), sendo os taninos, glicosídeos cianogênicos, alcaloides, sesquiterpenos, flavonoides e ácidos fenólicos, os principais responsáveis por tais propriedades (King \& Ambika 2002).

Os aleloquímicos, produtos do metabolismo secundário, são produzidos em diferentes órgãos da planta, sendo que a concentração é variável entre tecidos e dependente de fatores ambientais (Delachiave et al. 1999). Estes compostos exercem influência em agroecossistemas, principalmente por ocasionarem efeitos fisiológicos negativos como a inibição da porcentagem e velocidade da germinação e a redução do crescimento inicial de plântulas (Macías et al. 2007), sendo estas, respostas secundárias de efeitos primários que ocorrem no processo metabólico das plantas afetadas (Pedrol et al. 2006). Além disso, podem se refletir em alterações em nível celular, fitormonal, fotossintético e respiratório, o que, indiretamente, pode interferir na produtividade agrícola e na biodiversidade local, devido a alterações na sucessão vegetal, na estrutura, dominância de certas espécies e composição das comunidades vegetais (Rizvi et al. 1992; Chou 1999; Chou 2006).

A influência destes compostos entre plantas dispostas em um mesmo ambiente é consequência da sua liberação por volatilização, lixiviação, decomposição de resíduos vegetais no solo ou exsudação radicular da planta doadora à receptora (Rice 1984). Essa ocorrência constitui vantagem seletiva para o doador por consistir em mecanismo de defesa adquirido ao longo do processo evolutivo (Chou 1999; Chou 2006), devendo ser enfatizado que sua ação é eficaz se a liberação é contínua para permitir que os efeitos persistam até as culturas subsequentes (Rodrigues et al. 1999).

O surgimento de plantas daninhas tolerantes aos herbicidas, usualmente empregados no seu controle, reflete na necessidade do estudo de novas substâncias com potencial de inibição da germinação ou do crescimento dessas espécies e cuja molécula possa ser sintetizada e comercializada em larga escala. Além disso, a produção orgânica tem se apresentado como mercado promissor motivando pesquisas aplicadas à alelopatia. Desse modo, bioensaios laboratoriais envolvendo investigações alelopáticas por meio de espécies indicadoras, assumem importância por permitirem o controle de condições ambientais e a exclusão da interação simultânea entre indivíduos que ocorrem em cultivos no campo (Inderjit \& Dakshini 1995) e permitem a avaliação de determinado acesso como produtor de compostos ale- lopáticos. Além disso, não há conhecimento sobre o estudo do potencial alelopático da espécie Piper mikanianum (Piperaceae), planta nativa da vegetação brasileira, de ocorrência da Amazônia até o Rio Grande do Sul (Lorenzi 2000), que forma agrupamentos vegetais, podendo exercer influência no estabelecimento de outras plantas devido ao possível potencial alelopático.

Nesse contexto, este trabalho objetivou avaliar a possível atividade alelopática de diferentes concentrações do extrato aquoso de folhas de Piper mikanianum sobre a germinação e o crescimento inicial de rabanete.

\section{Material e métodos}

Os bioensaios foram conduzidos em Laboratório de Fisiologia Vegetal, na Universidade Regional Integrada do Alto Uruguai e das Missões - Campus Frederico Westphalen - RS, no período compreendido entre outubro de 2009 a fevereiro de 2010.

O potencial alelopático de pariparoba [Piper mikanianum (Kunth) Steudel] foi avaliado a partir de extratos aquosos de folhas maduras e completamente expandidas, coletadas em formações vegetais secundárias, situadas na região do Médio Alto Uruguai do Estado do Rio Grande do Sul. Os extratos nas concentrações de 2, 4 e 8\% (p/v), foram obtidos a partir da trituração, em liquidificador, do material vegetal em destilada e deionizada, por cinco minutos em temperatura ambiente $\left( \pm 25^{\circ} \mathrm{C}\right)$, seguido de repouso por $24 \mathrm{~h}$, na ausência de luminosidade e sob refrigeração $\left( \pm 10^{\circ} \mathrm{C}\right)$. Posteriormente, os extratos foram submetidos à filtração simples em algodão hidrófilo e centrifugados a $4.000 \mathrm{rpm}$ por $6 \mathrm{~min}$. Os sobrenadantes constituíram os extratos a serem utilizados nos bioensaios. Os efeitos alelopáticos dos extratos sobre a germinação de sementes (bioensaio I) e o crescimento inicial de plântulas de rabanete (Raphanus sativus L., cv. Crinsom Gigante) (bioensaio II) foram comparados com o controle (água destilada e deionizada - 0\%).

O bioensaio de germinação (Bioensaio I) foi realizado em placas de Petri de diâmetro $9 \mathrm{~cm}$ contendo duas folhas de papel Germitest esterilizadas, umedecidas com $7 \mathrm{~mL}$ dos extratos aquosos, discriminados pela concentração ou água destilada e deionizada. $\mathrm{O}$ experimento foi constituído de quatro tratamentos, cada tratamento com cinco repetições de 25 sementes distribuídas aleatoriamente. Todas as placas permaneceram em câmara de germinação (B.O.D.) a $25{ }^{\circ} \mathrm{C}$, sob iluminação constante mantida por quatro lâmpadas brancas fluorescentes de $25 \mathrm{~W}$, tipo luz do dia. Segundo Bravin et al. (2006), a irradiância média de duas lâmpadas equivale a $30 \pm 5 \mu \mathrm{mol} \mathrm{m} \mathrm{m}^{-2} \mathrm{~s}^{-1}$. A contagem da germinação foi realizada diariamente, sempre no mesmo horário, até totalizar cinco dias após a semeadura. Foram consideradas germinadas sementes dotadas de $2 \mathrm{~mm}$ de protusão radicular (Ferreira \& Aquila 2000). A porcentagem de germinação (PG), velocidade de germinação (VG) 
e índice de velocidade de germinação (IVG) seguiram recomendações de Vieira \& Carvalho (1994). O Índice de efeito alelopático (RI) foi calculado de acordo com Gao et al. (2009) pela seguinte equação:

$$
\mathrm{RI}=1-\mathrm{C} / \mathrm{T}(\mathrm{T} \geq \mathrm{C}) \text { ou } \mathrm{RI}=\mathrm{T} / \mathrm{C}-1(\mathrm{~T}<\mathrm{C})
$$

sendo:

$\mathrm{C}=$ velocidade de germinação do controle

$\mathrm{T}=$ velocidade de germinação do tratamento.

A velocidade de germinação foi calculada de acordo com Gao et al. (2009):

Velocidade de germinação $(\%)=\sum(\mathrm{Gt} / \mathrm{D}) / \sum(\mathrm{Gc} / \mathrm{Dx} 100)$ sendo:

$\mathrm{Gt}=$ número de sementes germinadas diariamente do tratamento.

$\mathrm{Gc}=$ número de sementes germinadas diariamente do controle.

$\mathrm{D}=$ número de dias correspondente.

No bioensaio de crescimento inicial (Bioensaio II) foi efetuada a padronização do tamanho das plântulas a serem submetidas aos extratos, sendo para isso, conduzidos bioensaios de germinação similarmente ao descrito anteriormente para avaliação de germinação. Após a protusão da radícula, plântulas que apresentaram radícula de $2 \mathrm{~mm}$ foram transferidas para caixas tipo gerbox, dotadas com duas folhas de papel Germitest esterilizadas e contendo 15 $\mathrm{mL}$ dos extratos aquosos ou água destilada e deionizada, perfazendo quatro tratamentos com cinco repetições de 10 plântulas. As caixas foram dispostas em câmara de germinação nas mesmas condições descritas no Bioensaio I. Após sete dias, o comprimento do hipocótilo e da radícula com o uso de régua milimetrada foram avaliados. Além desses, foram aferidas em balança analítica, a massa fresca das plântulas e a massa seca, após acondicionamento em sacos de papel pardo e secagem em $70^{\circ} \mathrm{C}$ até massa constante. O conteúdo de água (CA) foi obtido de acordo com Marenco \& Lopes (2005) e o teor de clorofila ( $a, b$ e total) de acordo com metodologia descrita por Arnon (1949). O pH dos diferentes extratos utilizados foi aferido por pHmetro e a determinação da concentração molar dos extratos foi realizada pelo método de Chardakov, sendo seus valores transformados em MPa (Salisbury \& Ross 1992). Os testes de germinação com potencias osmóticos iguais aos dos extratos foram determinados segundo especificações de Michel \& Kaufmann (1973).

O delineamento experimental adotado foi inteiramente casualizado. Os dados foram submetidos à análise de variância e se significativo, as médias foram comparadas a 5\% de probabilidade, pelo teste de Tukey por meio do programa SAS 8.0 (SAS Institute Inc. Cary, NC, USA).

\section{Resultados}

\section{Bioensaio de Germinação (Bioensaio I)}

Os efeitos dos extratos aquosos de folhas de Piper mikanianum sobre a germinação das sementes de rabanete foram significativos. A porcentagem de germinação (PG) foi reduzida em todos os tratamentos contendo extratos, sendo crescente ao aumento da concentração (Tab. 2). Quanto ao número de dias que as sementes levaram para germinar, a partir da velocidade de germinação (VG), foi possível verificar que houve aumento de VG na concentração de $4 \%$, sendo mais marcante o efeito do extrato de concentração 8\% (Tab. 2). Os resultados para o índice de velocidade de germinação (IVG) foram expressivos, ocorrendo significativa redução do número de sementes germinadas por dia em relação ao controle, sendo esta resposta dose dependente (Tab. 2).

Em relação ao índice de efeito alelopático (RI), que indica estímulo de germinação caso apresente valores positivos em relação ao controle, enquanto valores negativos estão relacionados à inibição, é possivel observar na Tab. 2, que, a partir da concentração $2 \%$ houve redução da germinação, sendo os efeitos inibitórios crescentes com o aumento da concentração dos extratos.

\section{Bioensaio de crescimento inicial (Bioensaio II)}

Os extratos de $P$. mikanianum provocaram redução no comprimento da radícula de plântulas de rabanete, sendo os efeitos inibitórios crescentes com o aumento da concentração dos extratos utilizados (Tab. 3). A resposta de crescimento do hipocótilo variou de acordo com os extratos. A concentração de $2 \%$ estimulou o crescimento, enquanto que a concentração de $8 \%$ resultou em efeito inibitório em relação às demais concentrações (Tab. 3). A massa fresca das plântulas crescidas na presença do extrato a $8 \%$ diminuiu significativamente quando comparado ao controle (Tab. 4). Por outro lado, a massa seca não foi influenciada, independente da concentração de extrato utilizada (Tab. 4). O conteúdo de água das plântulas diferiu apenas na concentração de $8 \%$ com redução do parâmetro em relação aos demais tratamentos (Tab. 4).

Para os teores de clorofila $a$, os tratamentos não diferiram do controle (Tab. 5). Os teores de clorofila $b$ e total aumentaram nas plântulas sob as menores concentrações de extrato e foram similares ao controle para a concentração $8 \%$ (Tab. 5).

\section{Características físico-quimicas}

A análise do $\mathrm{pH}$ dos extratos aquosos de folhas frescas $P$. mikanianum mostrou reduzida variação de valores e baixa acidez, estando os valores entre 6,51 a 6,86. Os valores de potencial osmótico variaram entre $-0,0146$ a -0,0488 MPa (Tab. 1).

Em relação à germinação de sementes de rabanete em diferentes concentrações de soluções de polietileno glicol 
Tabela 1. Características físico-químicas de extratos aquosos de folhas de Piper mikanianum.

\begin{tabular}{lcc}
\hline Concentração & $\mathrm{pH}$ & $\Psi_{\mathrm{s}}(\mathrm{MPa})$ \\
\hline Controle & 6,86 & 0,0000 \\
$2 \%$ & 6,75 & $-0,0146$ \\
$4 \%$ & 6,53 & $-0,0317$ \\
$8 \%$ & 6,51 & $-0,0488$ \\
\hline
\end{tabular}

$\Psi_{\mathrm{s}}=$ Potencial osmótico.

Tabela 2. Porcentagem de germinação (PG), Velocidade de germinação (VG), Índice de velocidade de germinação (IVG) e índice de efeito alelopático (RI) de sementes de rabanete sob influência de diferentes concentrações de extratos aquosos de folhas de Piper mikanianum.

\begin{tabular}{ccccc}
\hline Concentração & PG (\%) & VG $\left(\right.$ dias $\left.^{-1}\right)$ & IVG & RI \\
\hline Controle & $97 \pm 3,83 \mathrm{a}$ & $1,18 \pm 0,09 \mathrm{c}$ & $22,38 \pm 1,48 \mathrm{a}$ & 0 \\
$2 \%$ & $78 \pm 4,00 \mathrm{~b}$ & $1,35 \pm 0,15 \mathrm{bc}$ & $16,48 \pm 1,30 \mathrm{~b}$ & $-0,26$ \\
$4 \%$ & $61 \pm 8,25 \mathrm{c}$ & $1,55 \pm 0,18 \mathrm{~b}$ & $11,69 \pm 1,30 \mathrm{c}$ & $-0,47$ \\
$8 \%$ & $33 \pm 8,87 \mathrm{~d}$ & $2,36 \pm 0,24 \mathrm{a}$ & $4,42 \pm 1,58 \mathrm{~d}$ & $-0,80$ \\
\hline
\end{tabular}

*Médias \pm desvio padrão. Médias seguidas de letras iguais nas colunas não diferem entre si pelo teste de Tukey a $5 \%$ de probabilidade.

Tabela 3. Comprimento do hipocótilo e da radícula de plântulas de rabanete sob influência de diferentes concentrações de extratos aquosos de folhas de Piper mikanianum.

\begin{tabular}{ccc}
\hline Concentração & $\begin{array}{c}\text { Comprimento } \\
\text { hipocótilo }(\mathrm{cm})\end{array}$ & $\begin{array}{c}\text { Comprimento da } \\
\text { radícula }(\mathrm{cm})\end{array}$ \\
\hline Controle & $2,42 \pm 0,42 \mathrm{~b}$ & $10,05 \pm 1,01 \mathrm{a}$ \\
$2 \%$ & $3,18 \pm 0,40 \mathrm{a}$ & $4,68 \pm 0,88 \mathrm{~b}$ \\
$4 \%$ & $3,10 \pm 0,09 \mathrm{ab}$ & $2,25 \pm 0,24 \mathrm{c}$ \\
$8 \%$ & $1,77 \pm 0,20 \mathrm{c}$ & $0,63 \pm 0,14 \mathrm{~d}$ \\
\hline
\end{tabular}

${ }^{*}$ Médias \pm desvio padrão. Médias seguidas de letras iguais nas colunas não diferem entre si pelo teste de Tukey a $5 \%$ de probabilidade.

Tabela 4. Biomassa fresca (MF), biomassa seca (MS) e conteúdo de água (CA) de plântulas de rabanete sob influência de diferentes concentrações de extratos aquosos de folhas de Piper mikanianum.

\begin{tabular}{cccc}
\hline Concentração & MF $(\mathrm{g})$ & MS $(\mathrm{g})$ & CA (\%) \\
\hline Controle & $0,90 \pm 0,04$ a & $0,054 \pm 0,002 \mathrm{a}$ & $93,10 \pm 0,10 \mathrm{a}$ \\
$2 \%$ & $0,98 \pm 0,13 \mathrm{a}$ & $0,057 \pm 0,005 \mathrm{a}$ & $94,13 \pm 0,25 \mathrm{a}$ \\
$4 \%$ & $0,85 \pm 0,07 \mathrm{ab}$ & $0,053 \pm 0,004 \mathrm{a}$ & $93,72 \pm 0,25 \mathrm{a}$ \\
$8 \%$ & $0,69 \pm 0,11 \mathrm{~b}$ & $0,063 \pm 0,015 \mathrm{a}$ & $90,87 \pm 1,93 \mathrm{a}$ \\
\hline
\end{tabular}

${ }^{*}$ Médias \pm desvio padrão. Médias seguidas de letras iguais nas colunas não diferem entre si pelo teste de Tukey a $5 \%$ de probabilidade.

Tabela 5. Teor de clorofila $a$, clorofila $b$ e clorofila total da parte aérea de plântulas de rabanete sob influência de diferentes concentrações de extratos aquosos de folhas de Piper mikanianum.

\begin{tabular}{cllc}
\hline Concentração & $\begin{array}{c}\text { Clorofila } a \\
\left(\mathrm{mg} \mathrm{g}^{-1} \mathrm{MF}\right)\end{array}$ & $\begin{array}{c}\text { Clorofila } b \\
\left(\mathrm{mg} \mathrm{g}^{-1} \mathrm{MF}\right)\end{array}$ & $\begin{array}{c}\text { Clorofila total } \\
\left(\mathrm{mg} \mathrm{g}^{-1} \mathrm{MF}\right)\end{array}$ \\
\hline Controle & $1,26 \pm 0,20 \mathrm{ab}$ & $0,55 \pm 0,24 \mathrm{c}$ & $1,81 \pm 0,38 \mathrm{~b}$ \\
$2 \%$ & $1,50 \pm 0,03 \mathrm{a}$ & $1,07 \pm 0,24 \mathrm{ab}$ & $2,58 \pm 0,23 \mathrm{a}$ \\
$4 \%$ & $1,56 \pm 0,26 \mathrm{a}$ & $1,23 \pm 0,05 \mathrm{a}$ & $2,79 \pm 0,29 \mathrm{a}$ \\
$8 \%$ & $1,09 \pm 0,13 \mathrm{~b}$ & $0,76 \pm 0,18 \mathrm{bc}$ & $1,85 \pm 0,31 \mathrm{~b}$ \\
\hline
\end{tabular}

${ }^{*}$ Médias \pm desvio padrão. Médias seguidas de letras iguais nas colunas não diferem entre si pelo teste de Tukey a $5 \%$ de probabilidade.
6000 pode-se observar que as soluções de potencial osmótico equivalente ao potencial osmótico dos extratos aquosos $P$. mikanianum não influenciaram na germinação de sementes de rabanete, nas avaliações de porcentagem de germinação (PG), velocidade de germinação (VG) e índice de velocidade de germinação (IVG) (Tab. 6).

\section{Discussão}

A germinação das sementes de rabanete foi severamente inibida pela ação dos extratos aquosos de folhas de $P$. mikanianum (Tab. 2). A intensidade do efeito alelopático ocasionado pelos extratos aquosos depende do tipo de tecido usado para a extração e da concentração de aleloquímicos, estando diretamente relacionados à espécie (Wu et al. 2009). Pode se observar uma relação dose dependente entre a germinação e os extratos, uma vez que, ao aumentar a concentração dos extratos, ocorreu uma redução significativa da germinação das sementes de rabanete, possivelmente relacionada ao aumento na quantidade de aleloquímicos da solução.

Estudos têm demonstrado que extratos aquosos de diferentes tecidos possuem efeitos alelopáticos sobre a germinação de sementes. Segundo Zhang et al. (2010), a porcentagem de germinação de sementes de rabanete diminuiu com o aumento da concentração de extratos aquosos obtidos de raízes de eucalipto (Eucalyptus grandis W. Hill ex Maiden). Extratos aquosos de Aristolochia esperanzae O. Kuntze reduziram a porcentagem de germinação e aumentaram a velocidade de germinação de sementes de alface e rabanete (Gatti et al. 2004). Resultados de PG e VG semelhantes aos obtidos no presente trabalho também foram encontrados para sementes de alface e de rabanete sob influência de extratos aquosos de caules e folhas de Andira humilis Mart. ex Benth, onde os efeitos inibitórios proporcionais ao aumento da concentração dos extratos (Periotto et al. 2004). Extratos aquosos de frutos Phytolacca dioica L. reduziram significativamente a PG e IVG de sementes de alface e picão-preto (Borella \& Pastorini, 2010).

O índice de efeito alelopático RI foi utilizado por Khong et al. (2002) e por Abdelgaleil \& Hashinaga (2007) para demonstrar os efeitos causados pelos extratos em bioensaios Os valores de RI variam de acordo com o impacto dos efeitos, sejam positivos ou negativos (Khong et al. 2002). Extratos aquosos de Hemisepta lyrata Bunge provocaram efeitos inibitórios sobre a germinação de sementes de rabanete, indiferentemente da concentração utilizada (Gao et al. 2009). Zhang et al. (2010) também relataram efeitos negativos ocasionados pelos extratos de eucaplipto sobre o rabanete. Segundo Labouriau \& Agudo (1987), variações acentuadas nos parâmetros testados indicam a perda de sincronia nas reações metabólicas da germinação, demonstrando heterogeneidade na fisiologia das sementes submetidas ao extrato.

Respostas diferenciadas foram observadas quanto ao comprimento das plântulas de rabanete, pois os extratos com menores concentrações estimularam o crescimento do hipo- 
Tabela 6. Germinação de sementes de rabanete sob diferentes concentrações de soluções de PEG 6.000 .

\begin{tabular}{lccc}
\hline Concentração $(\mathrm{MPa})$ & PG $(\%)$ & VG $\left(\right.$ dias $\left.^{-1}\right)$ & IVG \\
\hline 0,000 (controle) & $95 \pm 3,82 \mathrm{a}$ & $1,33 \pm 0,07 \mathrm{a}$ & $20,41 \pm 0,77 \mathrm{a}$ \\
$-0,0146(2 \%)$ & $94 \pm 2,30 \mathrm{a}$ & $1,25 \pm 0,10 \mathrm{a}$ & $20,58 \pm 1,14 \mathrm{a}$ \\
$-0,0317(4 \%)$ & $95 \pm 3,82 \mathrm{a}$ & $1,29 \pm 0,09 \mathrm{a}$ & $20,75 \pm 0,77 \mathrm{a}$ \\
$-0,0488(8 \%)$ & $94 \pm 2,30 \mathrm{a}$ & $1,38 \pm 0,18 \mathrm{a}$ & $19,50 \pm 1,84 \mathrm{a}$ \\
\hline
\end{tabular}

${ }^{*}$ Médias \pm desvio padrão. Médias seguidas de letras iguais nas colunas não diferem entre si pelo teste de Tukey a $5 \%$ de probabilidade.

cótilo e com o aumento na concentração ocorreu tendência à redução no comprimento. $\mathrm{O}$ estímulo no crescimento de plântulas vem sendo rotineiramente descrito em trabalhos relacionados à alelopatia e possivelmente, este processo esteja relacionado à influência do extrato sobre a produção fitormonal da espécie alvo ou aumento na sensibildiade de seus tecidos (Rice 1984). Segundo Hong et al. (2004), o crescimento maior das plântulas em menores concentrações de extratos pode ser um mecanismo de proteção.

$\mathrm{O}$ aumento da concentração do extrato ocasionou redução significativa no crescimento da radícula (Tab. 3). Em geral, as raízes são mais sensíveis às substâncias presentes nos extratos comparativamente às demais estruturas da plântula (Chon et al. 2000). Esta ocorrência deve-se ao fato das raízes estarem em contato direto e prolongado com o extrato e aos aleloquímicos, em relação às demais estruturas da plântula (Chung et al. 2001) e/ou a reflexo da fisiologia distinta entre as estruturas (Aquila et al. 1999; 2004). Assim, é possível inferir que, nas concentrações de 4 e $8 \%$, o crescimento da radícula foi fortemente afetado, indicando que concentrações mais elevadas do extrato de P. mikanianum possuem capacidade fitotóxica em plântulas de rabanete.

Efeitos alelopáticos semelhantes aos efeitos de P. mikanianum sobre o rabanete também foram encontrados por outros autores. Para Zhang et al. (2010), extratos de raízes de plantas jovens de eucalipto exerceram efeitos estimulatórios sobre a radícula de rabanete e feijão, nas menores concentrações e, em concentrações altas, exerceram efeitos tóxicos com redução do comprimento da radícula das plantas testadas. Extratos de casca (Parvez et al. 2004) e de folhas frescas (Parvez et al. 2003) de Tamarindus indica L. nas concentrações 1,5 e $10 \%$ provocaram reduções no comprimento da radícula e do hipocótilo de plântulas de rabanete, tomate, alface e pepino. Reduções de até $96 \%$ no comprimento da radícula de rabanete em resposta a dois sesquiterpenos de Magnolia grandiflora L. foram observadas por Abdelgaleil \& Hashinaga (2007). Da mesma forma, extratos de folhas de Passiflora edulis reduziram significativamente o comprimento da radícula e da parte aérea de plântulas de rabanete (Khanh et al. 2006).

Os efeitos ocasionados sobre o comprimento das plântulas não se estenderam a alterações significativas na massa seca das plântulas de rabanete (Tab. 4). Essa resposta pode ser relacionada, segundo a um investimento diferenciado de matéria orgânica, ou na raiz ou na parte aérea, influenciada diretamente pelo tipo e concentração do extrato (Gatti et al. 2004). A redução da biomassa fresca das plântulas de rabanete com extratos na concentração $8 \%$ pode estar relacionada à redução do conteúdo de água (Tab. 4), decorrente da ação dos extratos. Extratos de folhas e cascas de tronco de canela-sassafrás [Ocotea odorifera (Vell.) Rohwer] provocaram aumento na massa fresca de radícula de plântulas de sorgo, sem afetar a massa fresca da parte aérea. No entanto, a massa seca tanto das raízes quanto da parte aérea foi afetada em todas as concentrações testadas (Carmo et al. 2007). Segundo Medeiros \& Lucchesi (1993), os extratos de ervilhaca não interferiram na matéria seca de plântulas de alface.

Extratos aquosos de diferentes órgãos de Peganum harmala L., nas concentrações de 12 e 16\%, afetaram significativamente os teores de clorofila $b$ e total de plântulas de Avena fatua L. e Convolvulus arvensis L., não alterando os teores de clorofila $a$. Os efeitos mais severos foram observados nos tratamentos com extratos de folhas, seguido de extratos de caules e raízes de Peganum harmala (Sodaeizadeh et al. 2009). Efeitos semelhantes foram observados nos bioensaios de rabanete, no qual concentrações menores aumentaram os teores de clorofila $b$ e total não alterando os teores de clorofila $a$. Segundo Borella et al. (2009), extratos aquosos de folhas frescas e secas de Persea americana Mill. aumentaram os teores de clorofila $a, b$ e total de plântulas de alface. A redução ou o aumento da clorofila nos tratamentos pode ser atribuído à inibição ou estímulo da biossíntese de clorofila (Yang et al. 2004). Rice (1984) sugere que compostos alelopáticos podem influenciar na rota de síntese de precursores de porfirina da biossíntese de clorofila. $\mathrm{O}$ aumento dos teores de clorofila (Tab. 5), quando submetidos aos extratos de 2 e $4 \%$, podem estar relacionados ao aumento do comprimento da parte aérea (Tab. 3).

Extratos aquosos de folhas de Piper mikanianum possivelmente possuem compostos alelópaticos, que foram extraídos pela água e exerceram ação alelopática sobre sementes e plântulas de rabanete, reduzindo a germinação e o crescimento inicial desta espécie.

\section{Referências}

Abdelgaleil, S.A.M. \& Hashinaga, F. 2007. Allelopathic potential of two sesquiterpene lactones from Magnolia grandiflora L. Biochemical Systematics and Ecology 35: 737-742.

Aquila, M.E.A., Ungaretti, J.A.C. \& Michelin, A. 1999. Preliminary observation on allelopathic activity in Achyrocline satureoides (Lam.) DC. Acta Horticulturae 502: 383-388.

Arnon, D.I. 1949. Copper enzymes in isolated chloroplasts. Polyphenoloxidase in Beta vulgaris. Plant Physiology 24: 1-15.

Borella, J. \& Pastorini, L.H. 2010. Efeito alelopático de frutos de umbu (Phytolacca dioica L.) sobre a germinação e crescimento inicial de alface e picão-preto. Ciência e Agrotecnologia 35(5): 1129-1135.

Borella, J.; Wandscheer, A.C.D.; Bonatti, L.C. \& Pastorini, L. 2009. Efeito alelopático de extratos aquosos de Persea americana Mill. sobre Lactuca sativa L. Revista Brasileira de Biociências 7(3):260-265.

Bravin, I.C., Valentin, Y.Y. \& Yokoya, N.S. 2006. Formação de calos e regeneração de segmentos apicais de Hypnea musciformis (Wulfen) 
Lamouroux (Gigartinales, Rhodophyta): obtenção de culturas axênicas e efeitos da concentração do ágar. Revista Brasileira de Botânica 29(1): 175-182.

Carmo, F.M.S., Borges, E.E.L. \& Takaki, M. 2007. Alelopatia de extratos aquosos de canela-sassafrás (Ocotea odorifera (Vell.) Rohwer. Acta Botanica Brasilica 21(3): 697-705.

Chon, S.U., Coutts, J.H. \& Nelson, C.J. 2000. Effects of light, growth media, and seedling orientation on bioassays of alfalfa autotoxicity. Agronomy Journal 92: 715-720.

Chou, C.H. 2006. Introduction to allelopathy. In: Reigosa, M.J.; Pedrol, N. \& González, L. (Eds). Allelopathy: A physiological process with ecological implications. Dordrecht: Springer.

Chou, C.H. 1999. Roles of allelopathy in plant biodiversity and sustainable agriculture. Critical Reviews in Plant Sciences 18: 609-630.

Chung, I.M., Ahn, J.K. \& Yun, S.J. 2001. Assessment of allelopathic potential of barnyard grass (Echinochloa crus-gall) on rice (Oriza sativa L.) cultivars. Crop Protection 20: 921-928.

Delachiave, M.E.A., Rodrigues, J.D. \& Ono, E.O. 1999. Efeitos alelopáticos de losna (Artemisia absinthium L.) na germinação de sementes de pepino, milho, feijão e tomate. Revista Brasileira de Sementes 21(1): 265-269.

Ferreira, A.G. \& Aquila, M.E.A. 2000. Alelopatia: Uma área emergente da ecofisiologia. Revista Brasileira de Fisiologia Vegetal 12: 175-204.

Gao, X.; Li, M.; Gao, Z.; Li, C. \& Sun, Z. 2009. Allelopathic effects of Hemistepta lyrata on the germination and growth of wheat, sorghum, cucumber, rape, and radish seeds. Weed Biology and Management 9: 243-249.

Gatti, A.B., Perez, S.C.J.G. \& Lima, M.I.S. 2004. Efeito alelopático de Aristolochia esperanzae O. Kuntze na germinação e no crescimento de Lactuca sativa L. e Raphanus sativus L. Acta Botanica Brasilica 18(3): 459-472.

Hong, N.H.; Xuan, T.D.; Eiji, T. \& Khanh, T.D. 2004. Paddy weed control by higher plants from Southeast Asia. Crop Prot. 23: 255-261.

Inderjit \& Dakshini, K.M.M. 1995. On laboratory bioassays in allelopathy. The Botanical Review 61:28-44.

Inderjit \& Duke, S.O. 2003. Ecophysiological aspects of allelopathy. Planta 217: 529-539.

Khanh, T.D.; Chung, I.M.; Tawata, S. \& Xuan, T.D. 2006. Weed suppression by Passiflora edulis and its potential Allelochemicals. Weed Research 46: 296-303.

King, S.R. \& Ambika, R. 2002. Allelopathic plants. 5. Chromolaena odorata (L.). Allelopathy Journal 9: 35-41.

Khong, C.; Hu, F. \& Xu, X. 2002. Allelopathic potential and chemical constituents of volatiles from Ageratum conyzoides under stress. Journal of Chemical Ecology 28: 1173-1182.

Kobayashi, K. 2004. Factors affecting phytotoxic activity of allelochemicals in soil. Weed. Biol. Manag. 4: 1-7.

Labouriau, L.F.G. \& Agudo, M. 1987. On the physiology of seed germination in Salvia hispanica L. I. Temperatura effects. Anais da Academia Brasileira de Ciências 59: 37-56.
Lorenzi, H. 2000. Árvores Brasileiras: manual de identificação e cultivo de plantas arbóreas nativas do Brasil. São Paulo, Nova Odessa, Instituto Plantarum.

Macías, F.A., Molinillo, J.M.G., Varela, R.M. \& Galindo, J.C.G. 2007. Allelopathy - a natural alternative for weed Control. Pest Management Science 63: 327-348.

Marenco, R.A. \& Lopes, N.F. 2005. Fisiologia Vegetal: fotossíntese, respiração, relações hídricas e nutrição mineral. Viçosa, UFV.

Medeiros, A.R.M. \& Lucchesi, A.A. 1993. Efeitos alelopáticos da ervilhaca (Vicia sativa L.) sobre a alface em testes de laboratório. Pesquisa Agropecuária Brasileira 28: 9-14.

Michel, B.E. \& Kaufmann, M.R. 1973. The osmotic potential of polyethylene glicol 6000. Plant Physiology 51: 914-916.

Parvez, S.S.; Parvez, M.M.; Fujii, Y. \& Gemma, H. 2004. Differential allelopathic expression of bark and seed of Tamarindus indica L. Plant Growth Regulation 42: 245-252.

Parvez, S.S.; Parvez, M.M.; Nishihara, E.; Gemma, H. \& Fujii, Y. 2003. Tamarindus indica L. leaf is a source of allelopathic substance. Plant Growth Regulation 40: 107-115.

Pedrol, N.; González, L. \& Reigosa, M. J. 2006. Allelopathy and abiotic stress. In: Reigosa, M. J.; Pedrol, N. \& González, L. (Eds). Allelopathy: A physiological process with ecological implications. Dordrecht: Springer.

Periotto, F., Perez, S.C.J.G.A. \& Lima, M.I.S. 2004. Efeito alelopático de Andira humilis Mart. Ex Benth na germinação e no crescimento de Lactuca sativa L. e Raphanus sativus L. Acta Botanica Brasilica 18(3): 425-430.

Rice, E. L. 1984. Allelopathy. 2nd ed. New York, Academic Press.

Rizvi, S.J.H., Haque, H., Singh, V.K. \& Rizvi, V. 1992. A discipline called allelopathy. In: Rizvi, S.J.H. \& Rizvi, V. (Eds.). Allelopathy: basic and applied aspects. London, Chapman \& Hall.

Rodrigues, B.N., Passini, T. \& Ferreira, A.G. 1999. Research on allelopathy in Brazil. In: Narwal, S.S. (Eds.). Allelopathy update. New Hampshire, Science Publishers.

Salisbury, F.B.; Ross, C. 1992. Plant Physiology. Belmont, Wadsworth.

Sodaeizadeh, H.; Rafieiolhossanini M.; Havlík, J. \& Van Damme, P. 2009. Allelopathic activity of different plant parts of Peganum harmala L. and identification of their growth inhibitors Substances. Plant Growth Regulation 59: 227-236.

Vieira, R.D. \& Carvalho, N.M. 1994. Testes de vigor em sementes. Jaboticabal: Funep.

Wu, A.P.; Yu, H.; Gao, S.Q.; Huang, Z.Y.; He, W.M.; Miao, S.L. \& Dong, M. 2009. Differential belowground allelopathic effects of eaf and root of Mikania micrantha. Trees Struct. Funct. 23: 11-17

Zhang, D.; Zhang, J.; Yang, W. \& Wu, F. 2010. Potential allelopathic effect of Eucalyptus grandis across a range of plantation ages. Ecol. Res. 25: $13-23$

Yang, C.M.; Chang, I.F.; Lin, S.J. \& Chou, C.H. 2004. Effects of three allelopathic phenolics on chlorophyll accumulation of rice (Oryza sativa) seedlings: II. Stimulation of consumption-orientation. Bot. Bull. Acad. Sin. 45: 119-125. 